\title{
Will Virtual Reality Simulators End the Credentialing Arms Race in Gastrointestinal Endoscopy or the Need for Family Physician Faculty With Endoscopic Skills?
}

All important ideas pass through three stages. First, they are ridiculed. Second, they are violently opposed. Third, they are accepted as being self-evident.

\section{- Schopenhauer}

Twenty years ago I stumbled upon an idea that changed my life. In a study of preventive medicine behaviors by family physicians, the introduction of a new procedural technology (flexible gastrointestinal endoscopy) markedly improved the longstanding noncompliance of physicians and patients in the prevention of colorectal cancer. ${ }^{1,2}$

The fiberoptic bundles of short colonoscopy and flexible sigmoidoscopy translated into a reproducibly constant group of diagnostic advantages. ${ }^{3}$ Improved patient tolerance led to greater insertion depth and better diagnostic yield. Few, however, have commented on the process that led to displacement of old technology (rigid sigmoidoscopy) by a continuum of newer technologies (flexible sigmoidoscopy, endoscopic biopsy, and colonoscopy; and esophagogastroduodenoscopy [EGD]). 4,5 Even fewer have described the lengthy technology transfer curve ( 30 years) and the embarrassing resistance of established physicians who were trying to protect the status quo. ${ }^{6-8}$

Using fiberoptic endoscopy, teacher and learner could observe the visual findings simultaneously, ${ }^{9}$ which had not been possible with rigid sigmoidoscopy. For the first time teaching could be structured and effective. Although medical schools and residencies had claimed that training occurred, clearly for many minor in-office surgical procedures, it had not. ${ }^{10} \mathrm{With}$ this new and more teachable procedure, surely, I thought, things would improve rapidly. ${ }^{11}$ They did not. Down-

Submitted 12 August 1998.

From the Department of Family Medicine, University of Tennessee, Memphis. Address reprint requests to Wm. MacMillan Rodney, MD, Department of Family Medicine, University of Tennessee, 1111 Union Ave, Memphis, TN 38104. stream from education, clinical practice changes slowly unless scientific, economic, and political incentives are aligned. They are not.

The study by Tuggy ${ }^{12}$ in this issue of The fournal arrives on the heels of yet more data describing widespread and repeated neglect of cancer prevention behaviors by physicians. ${ }^{13-15}$ Why do we keep churning the same tired data? Will family physicians collectively awaken to the leadership opportunities staring them in the face? ${ }^{16,17} \mathrm{Or}$, will they quietly retreat into the politically correct comfort of generic primary care? 18

\section{The Credentialing Arms Race in Gastrointestinal Endoscopy}

As the architect of many programs that teach procedural skills for primary care physicians, I have taught at nationally accredited courses for a variety of specialties, including, but not limited to, internists, family physicians, obstetrician-gynecologists, and general surgeons. Credentialing criteria should be specialty neutral and should acknowledge within this group of procedural skills that there are three levels of complexity:

1. Unsedated flexible sigmoidoscopy and colonoscopy (including biopsy)

2. Colonoscopy or EGD using intravenous sedation or analgesia

3. Endoscopic electrosurgery, with the most frequent example being colonoscopic polypectomy

By current self-report, flexible sigmoidoscopy and nonsedated general colonoscopy skills (remember that the $65-\mathrm{cm}$ flexible sigmoidoscope was originally called the short colonoscope) are taught in more than 95 percent of all internal medicine, family medicine, and general surgery programs. To the best of my knowledge, obstetrics-gynecology has not chosen to emphasize these procedures as a fundamental skill, though there are exceptions.

For credentialing purposes, a letter from the 
residency director stating that the physician has had appropriate training, education, or experience could be sufficient documentation to grant provisional skills. In the American Academy of Family Physicians (AAFP) collaborative study, most experienced family physicians with previous rigid sigmoidoscopy experience acquired flexible sigmoidoscopy skills in slightly fewer than 15 supervised procedures. ${ }^{19}$ The American Society for Gastrointestinal Endoscopy has unilaterally escalated this number to 25 supervised procedures. The average family physician can use the flexible sigmoidoscopy within 10 to 15 supervised procedures. ${ }^{20}$

Physicians who can document 50 to 100 successful short colonoscope or flexible sigmoidoscopy experiences in a private practice have shown sufficient experience to be considered for advancement to colonoscopy or EGD privileges. First, however, they must have training, experience, or education in intravenous sedation analgesia. To me, this means, at a minimum, having taken and passed an advanced cardiac life support (ACLS) course at least once every 5 to 10 years.

If the physician has a letter from his or her residency director certifying 20 supervised EGD experiences, I believe that physician has sufficient experience for provisional privileges. The surgical societies want a minimum of 25 for EGD and 50 for colonoscopy. The gastroenterologists have escalated the training requirements to a minimum of 100 for EGD and 100 for colonoscopy. Published studies suggest that endoscopy-naive physicians should probably have an ACLS certificate, intravenous sedation and analgesia skills, and a minimum of 20 supervised experiences each for EGD and colonoscopy., ${ }^{4,21-23}$ The exact number might vary slightly, but evaluation of proficiency should come from nonbiased colleagues who teach and serve. Once provisional privileges are granted, a period of surveillance and reassessment will follow. Currently our university hospital credentials within the Department of Family Medicine on this basis. In 10 years there has been one perforation (mine), no lawsuits, and no mortality.

Therapeutic endoscopy is a separate and more complex issue. Clearly physicians should have satisfied the criteria for level 2 skills. At this point, they should also have a working knowledge and some training in electrosurgery for colonoscopic polypectomy. In lieu of documented training, experience, or proven ability, I recommend at least one continuing medical education (CME) course on electrosurgery skills. The AAFP scientific assembly gives an excellent course each year.

The AAFP scientific assembly also offers a 4hour examination for physicians who wish to show competence in the techniques of flexible sigmoidoscopy and colonoscopy. This examination includes a graded test of cognitive issues, recognition of lesions and disease, equipment manipulation, and case management. To the best of my knowledge, it is the only independent and objective assessment of actual skill.

Once provisional privileges are attained, the physician may be advanced to full and independent procedures after a period of proctorship. Proctorship can be defined as hand-on-hand supervision, at-the-elbow supervision, or immediately available supervision, or it can be retrospective (chart review) supervision. For example, some hospitals allow physicians with well-documented qualifications to start cases with a second physician somewhere in the hospital or on call with a minimum response time of 15 minutes. These are all acceptable definitions of proctorship.

Each physician should maintain a database such that indications, findings, complications, medications, and procedure times are available for review. Once 5 to 10 cases or 1 year's activity has passed, a decision may be made regarding advancement to full and unrestricted privileges. As with all surgical procedures, the physician should be required to maintain a procedural $\log$ that is available for review.

\section{No Accountable Infrastructure for Teaching Advanced Skills}

There is no uniform and accountable educational infrastructure for teaching procedural skills. While I believe that virtual reality is an important advance, this study 12 points out that the "control group had no training or preparation before performing their first live patient examination...." A better comparison or control group would be residents who had worked for 30 minutes with an experienced examiner in a colon model that has a flexible sigmoid loop before their first live patient examination, which is more or less the purpose of the structured CME course given annually at the AAFP. In fact, the procedural teaching courses at the annual scientific assembly were developed in response to the lack of this training in residencies. 
As a member of that original scientific program committee, I am amazed that 15 years later a substantial number of residencies do not provide adequate training in such simple skills as flexible sigmoidoscopy.

In a study of obstetric sonography teaching, 19 percent of residencies responded that sonography was irrelevant because they did not teach obstetrics in their residency program. ${ }^{24}$ These same residencies claimed the contrary while undergoing accreditation by the Residency Review Committee. It appears we have a great many residencies claiming to provide structured experiences while, in reality, not providing them. ${ }^{25}$

A weakness of Tuggy's study, therefore, is the comparison of one valid method of structured curriculum with the current nonsystem of random chance. The AAFP coursed on flexible sigmoidoscopy-colonoscopy was among the first to provide performance-based learning and competencybased testing. Tuggy should be complimented for putting another brick into that structure.

At the frontiers of family medicine some educators, such as Dr. Tuggy, are developing training standards for a system that might be best labeled performance-based learning (ie, specific goals, objectives, and hands-on structure) and competencybased testing (ie, minimize red-out times, minimize directional errors, increase the percentage of colonic mucosa visualized, and minimize the time necessary to do an adequate examination). Additionally, there is a dimension of this procedure known as disease recognition. Since 1995 the disease-recognition skills (ie, the cognitive dimension) be tested alongside the psychomotor dimension of the procedure.

Finally, I want to mention improvement in quantity and quality among training opportunities in family practice. 26,27 While skeptics continue to suggest dismantling teaching programs for office surgeries, such as gastrointestinal endoscopy, many believe the need will persist. ${ }^{28}$ After all, less than 20 percent of Americans receive indicated screening for colorectal cancer.

If a virtual reality simulator allows each residency director in this country to provide 5 hours of structured curriculum in flexible sigmoidoscopy to each resident, a major victory will be gained for the prevention of premature death from colorectal cancer. No such accountability currently exists, however. After 20 years, I have been unable to convince my own faculty that they must take time to write a meaningful letter of completion for each resident who graduates from our programs. This does not dampen my enthusiasm for continuing to work toward this goal.

I want to commend those who did such a fine job of developing what I believe is a useful tool. It has an incredible amount of promise. If there is to be an important contribution from Tuggy's study, however, this teaching tool must be placed properly within the context of the problem it proposes to solve. High-tech education is most effective when blended with high-touch educators, and vice versa.

\section{Procedurally Capable Family Practice Faculty-A Virtual Reality Future?}

Historians will reflect on the 20th century as a curious time during which physicians developed the miracles of organ transplantation, intensive care units, and wonder drugs galore. Simultaneously, most medical students and young physicians are being infantilized by taught helplessness in a taxsubsidized and featherbedded medical education system that steadfastly refuses to reform. ${ }^{16,29,30}$

Notorious examples of nonaccountability have resulted in such training programs as ACLS, advanced trauma life support (ATLS), and advanced life support in obstetrics (ALSO). Since medical schools and the American Board of Medical Specialties could not or would not enforce accountability for basic life-saving clinical skills, societies of nonacademic practicing physicians have filled the void. The American Heart Association developed ACLS training in the 1970 s to discriminate between those physicians who could effectively respond to a cardiac arrest and those who could not. In the early 1980s, the American College of Surgeons developed ATLS training to certify those physicians who could stabilize critically injured patients in shock. The public assumed that, after a minimum of 7 years of medical school and residency, physicians would have been taught and tested for these skills. They are not. Licensing by means of multiple-choice questions, although convenient for the test givers, does not reliably assess competency at the bedside of patients with life-threatening illness.

Correspondence and data provided to the AAFP Task Force on Obstetrics and Procedures, 1989-1995, detailed case after case of well-inten- 
tioned rhetoric but limited procedural teaching for residents. ${ }^{31-34}$ Ineffective curricula, overworked educators, politically besieged directors, and a lack of consensus on procedural training led to limited opportunities for acquiring procedural skills. $^{35}$ In 1989 one of my senior faculty commented that the Memphis family practice residencies were basically producing "well-trained social workers." Downstream from these residencies, class after class of young family physicians departed with lowered expectations and limited skills. Tom Stern, MD, had predicted this outcome in $1980 .{ }^{36}$

Because of documented educational needs unmet by medical schools and residencies, the AAFP established an annual maternity care course and an additional program in obstetrics-ALSO, despite the claims of skeptics that delivery of babies by family physicians was not worth resuscitating. These programs have survived, prospered, and multiplied. ${ }^{26}$ "If you build it, they will come."

The 1997 Residency Review Committee-Family Practice special requirements mandate that each family practice program have some faculty who actually deliver babies. Children learn what they see their parents do. "The hand that rocks the cradle..."

The medical specialty of family practice, in particular, staked part of its claim for recognition upon a promise to provide effective preventive care. Based on my own studies describing the physician's role in noncompliance, I traced the source of this problem to inadequate training, lukewarm academic support, the reimbursement system, political suppression, and taught helplessness. and I have proposed and supported several educational interventions. ${ }^{37-41}$

Residency directors, do each of your faculty teach at least one flexible sigmoidoscopy session per month? Have you budgeted time for this activity? Do you have a system describing accountability for the procedural and hospital skills of residents (and faculty)? ${ }^{34,35,41}$ Do you have documented progress reports of each resident's clinical skills at years 1,2 , and 3 ?

In my experience, many residency directors cannot produce these documents. Subsequently, many family practice residents have never started an intravenous line and do not feel comfortable managing simple fractures, delivering a baby, or performing flexible sigmoidoscopy. Perhaps resi- dents will have a chance to start learning these skills by using the virtual reality trainer described by Tuggy ${ }^{12}$ and others. ${ }^{42}$

Perhaps, if computer-assisted virtual reality and simulated patient experiences can be produced in sufficient quantity, much of residency training can be provided by paraprofessionals. Think of the financial savings that would accrue if corporate executives could replace expensive physician educators with nurses and "smart" machines. ${ }^{43}$

Wm. MacMillan Rodney, MD University of Tennessee, Memphis

\section{References}

1. Rodney WM, Johnson RA, Beaber RJ, Jonokuchi C, Kujubu D. Residency chart audit: preventive medicine practice as noted in the medical record. Fam Pract Res J 1982;1:140-51.

2. Rodney WM, Beaber RJ, Johnson RA, Quan M. Physician compliance with colorectal cancer screening (1978-1983): the impact of flexible sigmoidoscopy. J Fam Pract 1985;20:265-9.

3. Rodney WM, Felmar E. Why flexible sigmoidoscopy instead of rigid sigmoidoscopy? J Fam Pract 1984;19:471-6.

4. Rodney WM, Weber JR, Swedberg JA, Gelb DM, Coleman WH, Hocutt JE Jr, et al. Esophagogastroduodenoscopy by family physicians phase II: a national multisite study of 2,500 procedures. Fam Pract Res J 1993;13:121-31.

5. Hopper W, Kyker KA, Rodney WM. Colonoscopy by a family physician: a 9-year experience of 1048 procedures. J Fam Pract 1996;43:561-6.

6. Rodney WM. Family practice procedures. J Fam Pract 1995;40:223-4.

7. Rodney WM. The dilemma of required curriculum for emerging technologies in primary care. Fam Med 1997;29:584-5.

8. Scarpinato L. On-site colposcopy services. J Am Board Fam Pract 1998;11:80-1.

9. Rodney WM, Ounanian LL, Werblun MN. Second-generation video sigmoidoscopy. Am Fam Physician 1985;31:127-32.

10. Rodney WM, Richards E, Ounanian LL, Morrison JD. Constraints on the performance of minor surgery by family physicians: study of "mock" skin biopsy procedure. Fam Pract 1987;4:36-40.

11. Rodney WM. Flexible sigmoidoscopy and the despecialization of endoscopy. J Fam Pract 1986;23: 279-80.

12. Tuggy ML. Virtual reality flexible sigmoidoscopy simulator training: impact on resident performance. J Am Board Fam Pract 1998;11:426-33.

13. Dietrich AJ, Tobin JN, Sox CH, Cassels AN, Negron F, Young RG, et al. Cancer early-detection services in community health centers for the underserved: a randomized controlled trial. Arch Fam Med 1998;7:320-7.

14. Williams RB, Boles $M$, Johnson RE. A patient-initiated system for preventive health care. A randomized trial in community-based primary care practices. Arch Fam Med 1998;7:338-45. 
15. Rutfin MT. Can we change physicians' practices in the delivery of cancer-preventive services? Arch Fam Med 1998;7:317-9.

16. James D. Re-engineering versus learned helplessness. J Fam Pract 1998;47:27.

17. Garrison RL. The five generations of American medical revolutions. J Fam Pract 1995;40:281-7.

18. Inui TS, Williams W'T Jr, Goode L, Anderson RJ, Bhak KN, Forsyth JD, et al. Sustaining the development of primary care in academic medicine. Working Group on Sustaining the Development of Academic Primary Care. Acad Med 1998;73:245-57.

19. Rodney WM, Felmar E, Auslander M. AAFP-ASGE conjoint course on flexible sigmoidoscopy. Fam Pract Res J 1986;5:209-15.

20. Brill JR, Baumgardner DJ. Establishing proficiency in flexible sigmoidoscopy in a family practice residency program. Fam Med 1997;29:580-3.

21. Harper MB, Pope JB, Mayeaux EJ Jr, Davis TJ, Myers A, Lirette A. Colonoscopy experience at a family practice residency: a comparison to gastroenterology in general surgery services. Fam Med 1997; 29:575-9.

22. Carr KW, Worthington JM, Rodney WM, Gentry S, Sellers A, Sizemore J. Advancing from flexible sigmoidoscopy to colonoscopy in rural family practice. Tenn Med 1998;91(1):21-6.

23. Hocutt JE Jr, Rodney WM, Zurad EG, Tucker RS, Norris T. Esophagogastroduodenoscopy for the family physician. Am Fam Physician 1994;49:10916, 121-2.

24. Connor PD, Deutchman ME, Hahn RG. Training in obstetric sonography in family medicine residency programs: results of a nationwide survey and suggestions for a teaching strategy. J Am Board Fam Pract 1994;7:124-9.

25. Thomas JM, Bredfeldt R, Easterling G, Massie $M$. Esophagogastroduodenoscopy training in family practice programs. Fam Med 1997;29:572-4.

26. Harper MB, Mayeaux EJ Jr, Pope JB, Goel R. Procedural training in family practice residencies: current status and impact on resident recruitment. J Am Board Fam Pract 1995;8:189-94.

27. Brotzman GL, Apgar BS. Assessing colposcopic skills: the instructor's handbook. Fam Med 1998;30: 350-5.

28. Pfenninger JL. Colposcopy, LEEP, and other proce- dures: the role for family physicians. Fam Med 1996; 28:505-7.

29. Whitcomb ME. Correcting the oversupply of specialists by limiting residencies for graduates of foreign medical schools. N Engl J Med 1995;333:454-6.

30. Schroeder SA. Medicine's glut of "fighter pilots"; we have far too many highly paid specialists and a scarcity of family doctors; it will take generations to undo. Los Angeles Times 4 Mar 1992;111:B7, col 1 (Wed).

31. Rodney WM. A personal reflection from the AAFP task force on obstetrics. Tenn Fam Physician 1990; $1(3): 4-5$.

32. Rodney.WM. Obstetrics-enhanced family practice: an endangered species worth saving! Fla Fam Physician 1993;43(1):8-9.

33. Board of directors report to the 1995 congress. AAFP Task Force on Procedures. Kansas City, Mo: American Academy of Family Physicians, 1995.

34. Susman J, Rodney WM. Numbers, procedural skills and science: do the three mix? Am Fam Physician 1994:49:1591-2.

35. Sierpina VS, Volk RJ. Teaching outpatient procedures: most common settings, evaluation methods, and training barriers in family practice residencies. Fam Med 1998;30:421-3.

36. Stern $T$. As privileges erode, program quality will follow. Am Fam Physician 1980;22:86-8.

37. Rodney WM, Felmar E, Morrison J, Richards E, Cousin L. Colposcopy and cervical cryotherapy: feasible additions to the primary care physician's office practice. Postgrad Med 1987;81(8):79-82, 85-6.

38. Rodney WM. Screening flexible sigmoidoscopy: is it worthwhile? An affirmative view. J Fam Pract 1987; 25:601-4.

39. Rodney WM. Keeping family practice whole. Fam Pract Manage 1995;2:11-2.

40. Rodney WM. Office procedural training. J Am Board Fam Pract 1997; 10:175-6.

41. Rodney WM. Should any hospital-based training for family physicians persist? Fam Med 1998;30: 398-9.

42. Prystowsky JB, Darosa DA. Virtual reality: an educational tool for surgical training? Curr Surg 1998; 55:1557.

43. Lardner J. For nurses, a barrier broken. It's a test insurers are backing: can primary care work without doctors? US News World Rep 27 July 1998:58-61. 